\title{
A comparison of the Health Star Rating and nutrient profiles of branded and generic food products in Sydney supermarkets, Australia
}

\author{
Dong Hun Kim†, Wing Gi Amanda Liut, Anna Rangan and Luke Gemming* \\ The University of Sydney, Nutrition and Dietetics, School of Life and Environmental Sciences, Charles Perkins Centre, \\ Building D17 Johns Hopkins Drive (off Missenden Road), NSW 2006, Australia
}

Submitted 24 April 2018: Final revision received 23 November 2018: Accepted 28 January 2019: First published online 26 March 2019

\begin{abstract}
Objective: To compare the Health Star Rating (HSR) and the nutritional profile of branded and generic packaged foods in Australia.

Design: In-store audits of packaged food products capturing data on HSR and nutritional content to analyse differences between branded and generic foods across ten food categories.

Setting: The audit was conducted in four major supermarket chains across various locations within metropolitan Sydney regions, Australia.

Results: A total of 6269 products were analysed with $57 \%$ of generic products and $28 \%$ of branded products displaying an HSR. The median HSR of branded products was significantly greater than for generic products overall $(4.0 \mathrm{v} .3 \cdot 5$, $P<0.005)$ and in six out of ten food categories $(P<0.005)$. However, when branded products could be matched to their generic counterparts for paired comparisons ( $n$ 146), no statistical difference was observed in all ten food categories. Branded products that chose to display an HSR had significantly lower saturated fat and $\mathrm{Na}$, but higher fibre contents than branded products not displaying an HSR.

Conclusions: Our data show no difference in the HSR or nutrient profiles of similar branded and generic products that display HSR. Branded products appear to exploit the voluntary nature of the HSR scheme, preferentially displaying an HSR on healthier products compared with their generic counterparts.
\end{abstract}

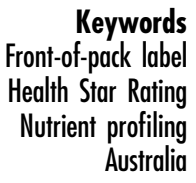

The Health Star Rating (HSR) system was introduced in Australia and New Zealand in 2014 as a voluntary frontof-pack labelling scheme, endorsed by the Australian government ${ }^{(1-3)}$. It is derived from a modified version of the Nutrient Profiling Scoring Criterion ${ }^{(1-5)}$ developed by Food Standards Australia New Zealand and features a ten-point star rating increasing in half-star increments, with the healthiest options displaying five stars ${ }^{(1-5)}$. The HSR was designed to assist consumers to easily compare the healthfulness of similar packaged foods ${ }^{(1-3,6)}$; however, development of the HSR system has been criticised for a lack of transparency and absence of an evidence base that supports the nutrient criteria cut-off points being predicative of health outcomes ${ }^{(7,8)}$. Limitations in the algorithms have been raised, as well as misalignment with the Australian Dietary Guidelines ${ }^{(9)}$.

Despite these limitations, the ongoing formal review of the HSR system reported significant uptake by the food industry since 2014 and indications that this initiative has encouraged manufacturers to reformulate food products to

$\dagger$ Dong Hun Kim and Wing Gi Amanda Liu are co-first authors. obtain a higher $\operatorname{HSR}^{(10,11)}$. The most recent data indicate that uptake has continued to increase, although the specific uptake of branded and generic (private label) products has not been reported ${ }^{(9)}$.

Retailers are continuing to expand their selection of generic products, with some supermarkets aiming for $40 \%$ of their product range to comprise generic products within the next five years ${ }^{(12)}$. Thus, there is a need to explore the HSR uptake and HSR scores between generic products and branded products. Limited research has investigated use of other front-of-pack labelling schemes with respect to branded and generic products. Studies in the UK, USA and Switzerland all concluded that generic products were nutritionally similar to their branded product counterparts ${ }^{(13-15)}$. However, only category-level comparisons were made. In Australia, a study found that generic products had lower mean $\mathrm{Na}$ content in comparison to their branded product counterparts but did not consider front-ofpack labelling schemes such as the $\mathrm{HSR}^{(16)}$.

The aim of the present study was to examine the HSR and nutrient profiles of branded $v$. generic products across 
different food categories, using unpaired and paired comparisons. Due to the voluntary nature of the HSR scheme, branded products with and without an HSR were also compared to assess any nutritional differences.

\section{Methods}

\section{Data collection}

The nutrient and labelling information from packaged foods was captured from four major supermarkets chains in metropolitan suburbs of Sydney, Australia: Woolworths, Coles, Aldi and IGA (Independent Grocers of Australia), between March and September 2017.

For every product, images were captured of the frontand back-of-pack nutrition information panel, ingredients list, country of origin, barcode and HSR using Lenovo Moto G4 smartphones. The brand, product name, packaging size, HSR and energy and nutrient contents (per $100 \mathrm{~g} / 100 \mathrm{ml}$ ) displayed in the nutrition information panel were recorded in an online Excel database. Different package sizes (including multipacks) of the same product were photographed and entered into the database as a separate item but were excluded from analysis if the nutrient profiles were identical.

Food products were categorised based on a modified version of the criteria used by the Food Monitoring Group's Food Categorisation System (see online supplementary material, Supplemental Table 1$)^{(17)}$. As some categories did not display an HSR for branded products, these were excluded from analysis (Discretionary Beverages and Eggs). The ten major categories were: Bread, Cereal, Convenience Food (Mixed Dishes), Dairy, Discretionary Food, Fish, Fruit and Vegetables, Meat and Alternatives, Snacks and Spreads (Supplemental Table 1). Within these major categories, products were further sorted into sub-categories and then food types (using the AUSNUT (Australian Food and Nutrient Database) codes $^{(18,19)}$; Supplemental Tables 2 and 3). For example, there were fifteen types of breakfast cereal in the Cereal category, and for each individual type, the number of branded products and generic products were reported and averaged. Only products that had at least one pair of branded and generic comparison were used. Branded products were identified as those not sold exclusively by a specific supermarket and generic products were classified as those sold exclusively in Woolworths, Coles, IGA or Aldi (e.g. Homebrand, \$martbuy, Black \& Gold and Aldiexclusive products).

\section{Data analysis}

Data cleaning involved removing duplicates and crosschecking outliers against original photographs. For data analysis, values ' $<5$ ', ' $<1$ ' and ' $<0 \cdot 1$ ' were replaced with '5', ' 1 ' and ' $0 \cdot 1$ ', respectively.
Statistical analyses were conducted using the statistical software package IBM SPSS Statistics for Windows version 24.0. The Shapiro-Wilks $W$ test indicated data were not normally distributed and therefore non-parametric tests were utilised. The Mann-Whitney $U$ test was used to examine differences in HSR scores and nutrient contents between branded and generic product categories (Table 2), and between branded products with and without an HSR score (Table 4). Paired sample analysis was undertaken to examine differences between the same food types (i.e. comparing apples with apples). For the paired analysis, the Wilcoxon signed-rank test was used to compare HSR scores and nutritional profiles between branded and generic products (Table 3). All statistical analyses were two-tailed with $P<0.005$ denoting statistical significance. Ethics approval was not required for the present study.

\section{Results}

A total of 4284 branded and 1985 generic packaged products across the ten food categories were analysed. Overall, $28 \%$ of branded products and $57 \%$ of generic products displayed an HSR (Table 1). Large differences were observed between branded and generic products displaying the HSR in all categories. In particular, within Convenience Food, $34 \%$ of branded products displayed an HSR compared with $81 \%$ of generic products; and similarly, for Spreads ( $47 \%$ of branded products $v .84 \%$ of generic products displayed an HSR).

Table 2 shows the comparison of the median HSR and nutritional profile per $100 \mathrm{~g}$ between branded and generic products that display an HSR across the ten food categories (unpaired analysis). The overall median HSR for branded products was significantly greater than for generic products $(4.0 v .3 \cdot 5, P<0 \cdot 001)$. Six out of the ten food categories showed a significant difference in the median HSR $(P<0.005)$, with branded products revealing higher HSR than generic products. Within branded products, the median HSR of food categories ranged from 3.5 to $5 \cdot 0$, whereas the median HSR of generic products ranged from 1.0 to 4.5 . The greatest discrepancy in median HSR was observed in Discretionary Food, with branded products scoring a median HSR of $4 \cdot 0$, compared with 1.0 for the generic products $(P<0 \cdot 001)$. Similarly, for Snacks, the branded products had a median HSR of 4.0 while the generic products had a median HSR of $1.5(P<0 \cdot 001)$.

The overall nutritional content comparison revealed that branded products contained lower amounts of saturated fat and $\mathrm{Na}$, but higher amounts of protein, fibre and sugar than generic products.

Paired analyses were undertaken using a total of 146 pairs of branded and generic products that displayed an HSR across the ten categories (Table 3). Using this approach, no differences in HSR were observed within 
Table 1 Number of branded and generic products in each food category and the number and percentage of products with a Health Star Rating (HSR) captured from an audit of four major supermarkets chains in metropolitan suburbs of Sydney, Australia, March-September 2017

\begin{tabular}{|c|c|c|c|c|}
\hline \multirow[b]{2}{*}{ Category } & \multirow[b]{2}{*}{ Product type } & \multirow[b]{2}{*}{ Products $(n)$} & \multicolumn{2}{|c|}{ Products with HSR } \\
\hline & & & $n$ & $\%$ \\
\hline \multirow[t]{2}{*}{ Bread } & Branded & 245 & 57 & 23 \\
\hline & Generic & 96 & 60 & 63 \\
\hline \multirow[t]{2}{*}{ Cereal } & Branded & 375 & 235 & 63 \\
\hline & Generic & 111 & 70 & 63 \\
\hline \multirow[t]{2}{*}{ Convenience Food } & Branded & 580 & 196 & 34 \\
\hline & Generic & 374 & 302 & 81 \\
\hline \multirow[t]{2}{*}{ Dairy } & Branded & 594 & 97 & 16 \\
\hline & Generic & 154 & 35 & 23 \\
\hline \multirow[t]{2}{*}{ Discretionary Food } & Branded & 599 & 163 & 27 \\
\hline & Generic & 214 & 99 & 46 \\
\hline \multirow[t]{2}{*}{ Fish } & Branded & 314 & 61 & 19 \\
\hline & Generic & 250 & 116 & 46 \\
\hline \multirow[t]{2}{*}{ Fruit and Vegetables } & Branded & 839 & 227 & 27 \\
\hline & Generic & 350 & 190 & 54 \\
\hline \multirow[t]{2}{*}{ Meat and Alternatives } & Branded & 304 & 63 & 21 \\
\hline & Generic & 283 & 175 & 62 \\
\hline \multirow{2}{*}{ Snacks } & Branded & 389 & 72 & 18 \\
\hline & Generic & 134 & 63 & 47 \\
\hline \multirow[t]{2}{*}{ Spreads } & Branded & 45 & 21 & 47 \\
\hline & Generic & 19 & 16 & 84 \\
\hline \multirow[t]{2}{*}{ Total } & Branded & 4284 & 1192 & 28 \\
\hline & Generic & 1985 & 1126 & 57 \\
\hline
\end{tabular}

any of the ten categories, although for all categories combined, the HSR was higher for branded products. Overall, branded products with HSR had significantly lower energy, saturated fat and higher fibre content than their generic counterparts.

Lastly, to determine whether branded products selectively displayed an HSR, a comparison of nutrient content was undertaken of branded products with and without utilising the star rating system (Table 4). Overall, branded products with an HSR had significantly lower saturated fat and $\mathrm{Na}$ contents and greater fibre content than branded products without an HSR (all $P<0 \cdot 005$ ).

\section{Discussion}

The present study compared the HSR and nutrient profiles of 6269 branded and generic products across ten food categories and was the first study to complete a paired analysis between specific branded and generic foods. Overall, use of the HSR on products was substantially greater for generic products (57\%) compared with branded products (28\%).

For these products the median HSR was significantly higher for branded compared with generic products, $4.0 \mathrm{v}$. 3.5 respectively. However, no categories showed any statistical differences between HSR or nutritional profile when branded products could be matched to generic counterparts for paired analysis. The conflicting result is likely due to the voluntary use of the HSR on food packaging, which allows food manufacturers to display an HSR only when desirable (higher HSR) ${ }^{(3)}$. Our data support this notion as branded products without an HSR had significantly higher saturated fat and $\mathrm{Na}$ and significantly less fibre, and supports commitments made by major Australian retailers to implement the HSR system across their own-product range ${ }^{(20,21)}$.

As the present study compared branded $v$. generic products with HSR, not entire categories, direct comparisons with similar research cannot be made. Nevertheless, similar to our findings, two studies in Switzerland (2014) and the UK (2016) reported that generic products were nutritionally similar to their branded product counterparts at a group level (no paired analysis was undertaken) ${ }^{(14,15)}$. While a previous study in Australia (2011 to 2013) found that generic products had lower mean $\mathrm{Na}$ content ${ }^{(16)}$, our findings revealed the opposite, with a significantly lower median Na content in branded products that displayed an HSR. The difference is likely due to product reformulation since the HSR system was introduced in 2014. Ni Mhurchu et al. compared over 15000 products within New Zealand between 2015 and 2016, which revealed significant reductions in $\mathrm{Na}$ and energy ${ }^{(22)}$. Additionally, it was found reformulations were greater in products that displayed an $\mathrm{HSR}^{(22)}$.

Our data also revealed a propensity for brand manufacturers to exploit the voluntary nature of the HSR by displaying an HSR only when desirable, with branded product medians for food categories being $\geq 3.5$ compared with $\geq 1.0$ for generic product medians. Such limitations of 


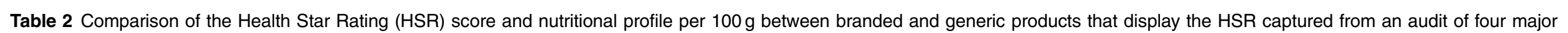
supermarkets chains in metropolitan suburbs of Sydney, Australia, March-September 2017: unpaired analysist

\begin{tabular}{|c|c|c|c|c|c|c|c|c|c|c|c|c|c|c|c|}
\hline \multirow[b]{2}{*}{ Category } & \multirow[b]{2}{*}{$n$} & \multicolumn{2}{|c|}{ HSR } & \multicolumn{2}{|c|}{ Energy (kJ) } & \multicolumn{2}{|c|}{ Saturated fat (g) } & \multicolumn{2}{|c|}{ Sugar (g) } & \multicolumn{2}{|c|}{$\mathrm{Na}(\mathrm{mg})$} & \multicolumn{2}{|c|}{ Protein (g) } & \multicolumn{2}{|c|}{ Fibre (g) } \\
\hline & & Median & IQR & Median & IQR & Median & IQR & Median & IQR & Median & IQR & Median & IQR & Median & IQR \\
\hline \multicolumn{16}{|l|}{ Bread } \\
\hline Branded & 57 & 4.0 & $4 \cdot 0-4 \cdot 5$ & 1010 & $950-1070$ & 0.6 & $0.4-0.7$ & $3 \cdot 1$ & $2 \cdot 2-4 \cdot 0$ & 400 & $370-400$ & 9.2 & $7 \cdot 8-10 \cdot 7$ & 6.5 & $4 \cdot 4-7 \cdot 7$ \\
\hline Generic & 60 & 4.0 & $3.5-4.0$ & 1060 & $1010-1130$ & 1.0 & $0.5-1.0$ & $3 \cdot 1$ & $2 \cdot 6-3 \cdot 9$ & 400 & $350-400$ & 8.6 & $7 \cdot 8-9.7$ & 4.3 & $3 \cdot 0-5 \cdot 8$ \\
\hline$P$ value & & \multicolumn{2}{|c|}{$<0.001^{*}$} & \multicolumn{2}{|c|}{$0.001^{*}$} & \multirow{2}{*}{\multicolumn{2}{|c|}{$<0.001^{*}$}} & \multirow{2}{*}{\multicolumn{2}{|c|}{0.760}} & \multirow{2}{*}{\multicolumn{2}{|c|}{0.493}} & \multirow{2}{*}{\multicolumn{2}{|c|}{0.240}} & \multicolumn{2}{|c|}{$<0.001^{*}$} \\
\hline \multicolumn{9}{|l|}{ Cereal } & & & & & & & \\
\hline Branded & 235 & 4.0 & $4 \cdot 0-4 \cdot 5$ & 1600 & $1540-1660$ & 1.2 & $0.4-1.8$ & $17 \cdot 1$ & $10 \cdot 2-22 \cdot 3$ & 120 & $20-270$ & $10 \cdot 1$ & $8 \cdot 2-12 \cdot 4$ & 8.55 & $7 \cdot 4-11$ \\
\hline Generic & 70 & 4.0 & $3.5-4.5$ & 1592 & $1548-1670$ & 1.3 & $1.0-1 \cdot 8$ & $16 \cdot 3$ & $5 \cdot 3-21.5$ & 75.5 & $11-311$ & $10 \cdot 8$ & $8 \cdot 4-12 \cdot 7$ & 8.6 & $5 \cdot 8-11 \cdot 4$ \\
\hline$P$ value & & \multicolumn{2}{|c|}{0.369} & & 83 & & & & 16 & & 372 & & & & 572 \\
\hline Convenience & Food & & & & & & & & & & & & & & \\
\hline Branded & 196 & 3.5 & $3 \cdot 5-4 \cdot 0$ & 323 & $197-454$ & 0.7 & $0 \cdot 3-1 \cdot 1$ & $2 \cdot 1$ & $1 \cdot 3-3 \cdot 2$ & 265 & $238-290$ & $3 \cdot 7$ & $1 \cdot 2-5 \cdot 7$ & 1.7 & $1 \cdot 2-2 \cdot 4$ \\
\hline Generic & 302 & 3.5 & $3.0-3 \cdot 5$ & 569 & $356-785$ & 1.9 & $1.0-3.3$ & 2.0 & $1 \cdot 3-3 \cdot 4$ & 272 & $221-350$ & $6 \cdot 0$ & $2 \cdot 8-9.2$ & 1.6 & $1 \cdot 2-2 \cdot 4$ \\
\hline$P$ value & & $<0$ & $01^{*}$ & $<$ & $.001^{*}$ & & $01^{*}$ & & 84 & 212 & 164 & & $01^{*}$ & 0 & 387 \\
\hline Dairy & & & & & & & & & & & & & & & \\
\hline Branded & 97 & 4.0 & $4 \cdot 0-5 \cdot 0$ & 260 & $158-350$ & 0.8 & $0.2-1.6$ & 4.6 & $2 \cdot 0-8 \cdot 7$ & 247 & $52-265$ & 3.5 & $3 \cdot 0-4 \cdot 3$ & 1.6 & $1.4-3.2$ \\
\hline Generic & 35 & 3.0 & $2 \cdot 0-4 \cdot 0$ & 1335 & $394-1600$ & $16 \cdot 4$ & $2 \cdot 2-21 \cdot 8$ & 2.5 & $1.0-4.7$ & 404 & $60-652$ & 14.7 & $4 \cdot 3-24 \cdot 6$ & 0.0 & 0.0 \\
\hline$P$ value & & $<0$ & $01^{*}$ & & $001^{*}$ & & $01^{*}$ & & $01^{*}$ & & $001^{*}$ & & $01^{*}$ & & $02^{*}$ \\
\hline Discretionar & Food & & & & & & & & & & & & & & \\
\hline Branded & 163 & 4.0 & $3 \cdot 0-4 \cdot 0$ & 1708 & $1622-1966$ & 3.9 & $2 \cdot 3-5 \cdot 2$ & 19 & $15 \cdot 6-27 \cdot 0$ & 40 & $15 \cdot 0-144$ & $7 \cdot 2$ & $6 \cdot 3-9 \cdot 1$ & 8.5 & $6 \cdot 0-10.5$ \\
\hline Generic & 99 & 1.0 & $0.5-2.0$ & 2040 & $1790-2130$ & $10 \cdot 5$ & $5 \cdot 8-14 \cdot 3$ & 30.8 & $22 \cdot 5-37 \cdot 4$ & 166 & $85 \cdot 0-311 \cdot 0$ & $5 \cdot 8$ & $4 \cdot 7-7 \cdot 0$ & 3.4 & $2 \cdot 4-4 \cdot 8$ \\
\hline$P$ value & & $<0$ & $01^{*}$ & & $001^{*}$ & & $01^{*}$ & & $001^{*}$ & & $001^{*}$ & & $01^{*}$ & $<0$ & $001^{*}$ \\
\hline Fish & & & & & & & & & & & & & & & \\
\hline Branded & 61 & 4.0 & $3.5-4.0$ & 788 & $654-873$ & 1.0 & $0.8-1.4$ & $1 \cdot 7$ & $1.0-2.9$ & 350 & $264-450$ & 13.5 & $11.0-18.5$ & 1.4 & $1 \cdot 1-2 \cdot 1$ \\
\hline Generic & 116 & 4.0 & $4 \cdot 0-4 \cdot 0$ & 599 & $437-866$ & 1.0 & $0.7-2.0$ & 1.0 & $0.0-1.8$ & 333 & $285-398$ & $19 \cdot 3$ & $14 \cdot 8-22 \cdot 9$ & 0.5 & $0.0-1 \cdot 0$ \\
\hline$P$ value & & 0.0 & & & $03^{*}$ & & 99 & & $001^{*}$ & & 454 & & $01^{*}$ & $<0$ & $001^{*}$ \\
\hline Fruit and Ve & etables & & & & & & & & & & & & & & \\
\hline Branded & 227 & 5.0 & $4.5-5.0$ & 195 & $161-281$ & 0.1 & $0.0-0.2$ & $6 \cdot 7$ & $2 \cdot 9-9 \cdot 2$ & 9 & $5-36$ & 1.0 & $0.5-2.6$ & $2 \cdot 0$ & $0.5-3.3$ \\
\hline Generic & 190 & 4.5 & $3.5-5 \cdot 0$ & 257 & $183-397$ & 0.2 & $0.1-1.0$ & 9.4 & $3 \cdot 3-13 \cdot 2$ & 12 & $5-50$ & 1.0 & $0.7-2.6$ & 2.5 & $1.0-4 \cdot 1$ \\
\hline$P$ value & & $<0$ & $01^{*}$ & & $001^{*}$ & & & & $001^{*}$ & & 780 & & & & 05 \\
\hline Meat and $\mathrm{Al}$ & ernatives & & & & & & & & & & & & & & \\
\hline Branded & 63 & 4.0 & $4 \cdot 0-5 \cdot 0$ & 921 & $640-1490$ & $1 \cdot 1$ & $0.6-4.4$ & $2 \cdot 7$ & $1 \cdot 0-4.4$ & 373 & $21-487$ & 14.6 & $9 \cdot 5-17 \cdot 8$ & $6 \cdot 0$ & $3.8-7.4$ \\
\hline Generic & 175 & 4.0 & $3 \cdot 0-4.5$ & 2410 & $912-2600$ & 4.9 & $3 \cdot 1-7 \cdot 2$ & 3.1 & $1 \cdot 7-5 \cdot 2$ & 278 & $10-400$ & $16 \cdot 0$ & $8 \cdot 4-21 \cdot 8$ & $6 \cdot 0$ & $3.1-8.9$ \\
\hline$P$ value & & 0.0 & & & $001^{*}$ & & $01^{*}$ & & 36 & & 128 & & & & 243 \\
\hline Branded & 72 & 4.0 & $4 \cdot 0-5 \cdot 0$ & 1870 & $1600-2100$ & $2 \cdot 3$ & $1 \cdot 7-5 \cdot 0$ & 11.8 & $4 \cdot 0-38 \cdot 7$ & 128 & $16-250$ & $12 \cdot 6$ & $7 \cdot 3-18 \cdot 4$ & 8.2 & $6 \cdot 8-10 \cdot 9$ \\
\hline Generic & 63 & 1.5 & $1.0-2.5$ & 2170 & $2080-2295$ & 7.6 & $3 \cdot 3-12 \cdot 4$ & 2.3 & $1 \cdot 0-7 \cdot 3$ & 517 & $409-760$ & 6.6 & $5 \cdot 6-8 \cdot 1$ & 3.5 & $2 \cdot 8-5 \cdot 1$ \\
\hline$P$ value & & $<0$ & $01^{*}$ & & $001^{*}$ & & $01^{*}$ & & $001^{*}$ & & $001^{*}$ & & $01^{*}$ & $<0$ & $001^{*}$ \\
\hline Spreads & & & & & & & & & & & & & & & \\
\hline Branded & 21 & $5 \cdot 0$ & $4.5-5.0$ & 2490 & $2430-2560$ & $6 \cdot 8$ & $5.9-8.8$ & $5 \cdot 2$ & $4 \cdot 1-5 \cdot 7$ & 200 & $10-255$ & 27.0 & $25 \cdot 0-29 \cdot 2$ & $7 \cdot 7$ & $6.1-7.9$ \\
\hline Generic & 16 & 4.5 & $4.0-4.5$ & 2640 & $2569-2688$ & 9.3 & $7.8-9.9$ & 4.9 & $1.8-7.9$ & 34 & 6-352 & $26 \cdot 0$ & $21 \cdot 2-27 \cdot 5$ & 6.9 & $5 \cdot 3-8 \cdot 7$ \\
\hline$P$ value & & 0.0 & & & $01^{*}$ & & & & 16 & & 280 & & & & 21 \\
\hline Total & & & & & & & & & & & & & & & \\
\hline Branded & 1192 & 4.0 & $3.5-4.5$ & 896 & 261-1620 & 0.9 & $0.3-2.1$ & $5 \cdot 2$ & $2 \cdot 3-15 \cdot 6$ & 158 & 20-290 & $7 \cdot 0$ & $2 \cdot 7-10 \cdot 6$ & $6 \cdot 0$ & $2 \cdot 0-8 \cdot 6$ \\
\hline Generic & 1126 & 3.5 & $3 \cdot 0-4 \cdot 0$ & 776 & $341-1495$ & 1.4 & $0.9-3.7$ & 3.4 & $1.6-10.5$ & 243 & $45-365$ & 5.9 & $2.7-9.5$ & $2 \cdot 4$ & $1 \cdot 4-4.3$ \\
\hline$P$ value & & $<0$ & $01^{*}$ & & 953 & & $01^{*}$ & & $001^{*}$ & & $001^{*}$ & & $1^{*}$ & $<0$ & $001^{\star}$ \\
\hline
\end{tabular}




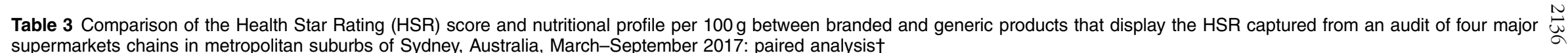

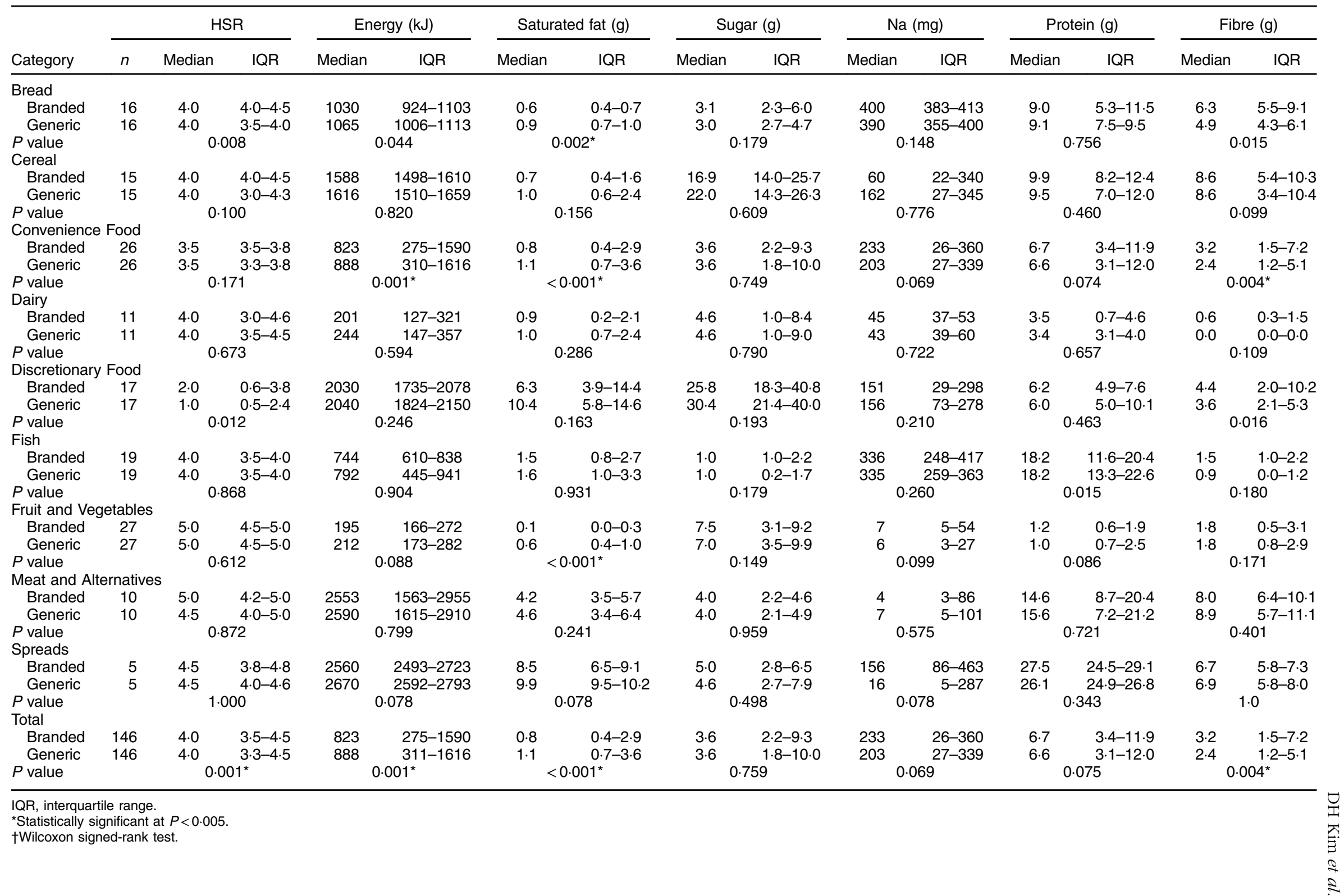




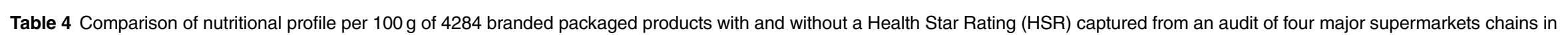
metropolitan suburbs of Sydney, Australia, March-September 2017†

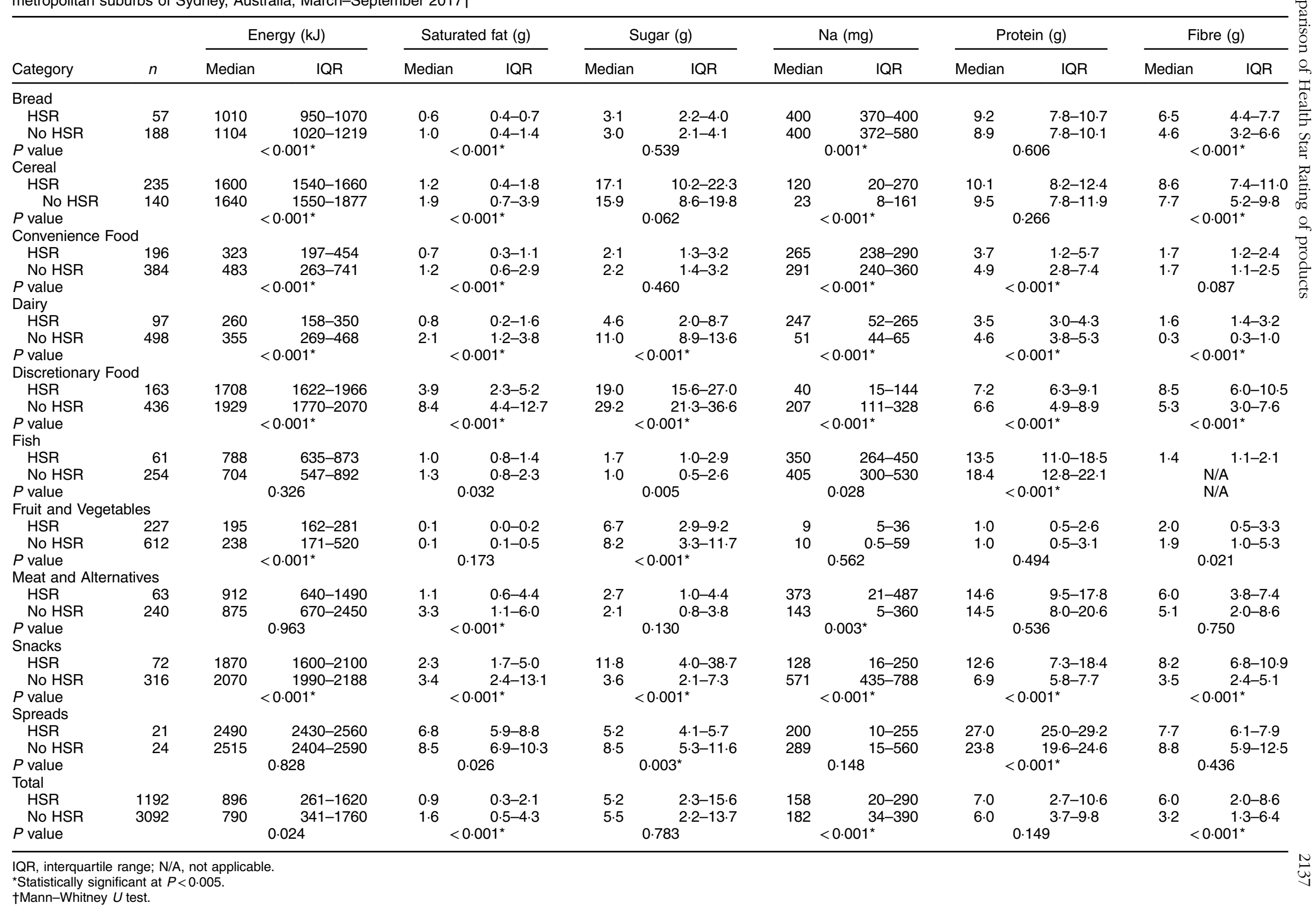


the voluntary HSR system were recently brought to light by Lawrence et al. when evaluating products within Australia categorised into food groups or discretionary foods ${ }^{(8)}$. The analysis revealed the median HSR for products that could be classified into one of the five food groups ranged between 3.5 and 4.5 , while the snack foods HSR median was $4 \cdot 0$. Additionally, $56 \cdot 7 \%$ of all discretionary foods had an $H S R \geq 2 \cdot 5$. These findings are reflected in our own results, with the median HSR being $>3.5$ for Convenience Food, Discretionary Food and Snacks for branded products.

A similar trend has also been demonstrated previously with other voluntary food labelling schemes. In 2003, Carter et al. investigated use of the Daily Intake Guide (DIG) in over 4000 discretionary products and found that $75 \%$ of the products that displayed a DIG did not report nutrients associated with negative health outcomes, such as sugar and saturated fat. Additionally, products without the DIG contained approximately ten times more saturated fat and twice as much sugar than products displaying the $\mathrm{DIG}^{(23)}$. Furthermore, generic products were found to display the DIG including saturated fat and sugar contents more frequently than branded products.

Limitations of the HSR system need to be considered when interpreting our data. Namely, the HSR algorithm can make discretionary foods appear healthier than reality, as foods are awarded stars within their category rather than across the wider food supply. Consequently, the high ratings achievable by many discretionary foods do not align with the Australian Dietary Guidelines ${ }^{(24)}$. For example, in our study the median HSR for discretionary branded Snacks (e.g. crisps and popcorn) was 4.0, which is important as high HSR scores could promote the consumption of discretionary foods, thus not aligning with the Guidelines. Consequently, strong arguments have been made to cap the HSR scores of discretionary foods to below 2.5 out of $5^{(7,8)}$. Moreover, as the HSR scoring system takes into account energy, saturated fat, protein and fibre to provide a single aggregate rating, this can veil the high sugar content. For example, branded Snacks (HSR $=4.0$ ) contained $11.8 \mathrm{~g} / 100 \mathrm{~g}$ sugar, significantly greater than generic Snacks with $2 \cdot 3 \mathrm{~g} / 100 \mathrm{~g}$ sugar and a median HSR of $1 \cdot 5$.

Some attempts to better align the HSR with dietary guidelines have been made. For example, Menday et al. explored whether substituting total sugar for added sugar would improve the capacity of the HSR to discriminate between 'core' (five food group foods) and 'discretionary' packaged foods ${ }^{(25)}$. The study found that using added sugar instead of total sugar assisted consumers to distinguish between 'core' foods and less healthy discretionary foods ${ }^{(25)}$.

To our knowledge, the present study is the first to investigate the use of the HSR and nutritional profile in a wide range of branded and generic packaged foods using both group-level and paired analyses. There were some limitations in our present study. The products were not strictly categorised according to the Australian Dietary Guidelines' five food group foods and discretionary foods as most categories contained a combination of both. This limited the interpretation of the HSR scores from a dietary guidelines perspective. Data were not collected for some categories including oils and speciality dietary products. Several food categories were also excluded from the analysis as very few branded products displayed an HSR, such as sugar-sweetened beverages, and data were collected for products in metropolitan Sydney only. However, with 6269 products analysed, the study provided a good representation of the products available to consumers in ten food categories, thus providing a reliable sample of the packaged food products within Sydney, Australia.

\section{Conclusion}

In conclusion, our data show there is no difference in the HSR or nutrient profiles of similar branded and generic products that display an HSR. As generic products are far more likely to contain an HSR than branded products, it appears manufacturers of branded products are exploiting the voluntary nature of the HSR scheme by preferentially displaying the HSR on healthier products. Our findings in conjunction with previous research highlight limitations of the HSR scheme that need consideration to achieve the Australian government's objective to guide and assist consumers to make informed, healthier dietary habits.

\section{Acknowledgements}

Acknowledgements: The authors would like to thank Eaden Roundtree, Irene Sangadi, Stephanie Liang, Ho Chun Terence Tong, Suzie Yang and Melissa Meier, who were involved in data collection and data cleaning. Financial support: This research received no specific grant from any funding agency in the public, commercial or notfor-profit sectors. Conflict of interest: None. Authorship: D.H.K. and W.G.A.L. are equal first authors. D.H.K. formulated the research idea; D.H.K. and W.G.A.L. designed and conducted the research; D.H.K., W.G.A.L., A.R. and L.G. analysed and interpreted the data; D.H.K., W.G.A.L., A.R. and L.G. wrote the paper. All authors read and approved the final manuscript. Ethics of buman subject participation: Not applicable.

\section{Supplementary material}

To view supplementary material for this article, please visit https://doi.org/10.1017/S1368980019000508 


\section{References}

1. Carrad AM, Louie JC, Yeatman HR et al. (2016) A nutrient profiling assessment of packaged foods using two starbased front-of-pack labels. Public Health Nutr 19, 2165-2174.

2. Talati Z, Pettigrew S, Kelly B et al. (2016) Consumers' responses to front-of-pack labels that vary by interpretive content. Appetite 101, 205-213.

3. Australian Government Department of Health and Ageing (2016) About Health Star Ratings. http://healthstarrating. gov.au/internet/healthstarrating/publishing.nsf/content/Abouthealth-stars (accessed March 2018).

4. Watson WL, Kelly B, Hector D et al. (2014) Can front-ofpack labelling schemes guide healthier food choices? Australian shoppers' responses to seven labelling formats. Appetite 72, 90-97.

5. Food Standards Australia New Zealand (2018) Overview of the Nutrient Profiling Scoring Criterion. http://www.foodstandards. gov.au/industry/labelling/Pages/Consumer-guide-to-NPSC. aspx (accessed July 2018).

6. Hamlin R \& McNeill L (2016) Does the Australasian 'Health Star Rating' front of pack nutritional label system work? Nutrients $\mathbf{8}, 327$.

7. Lawrence M \& Woods J (2018) Re: Jones et al., Nutrients 2018, 10, 501. Nutrients 10, 746.

8. Lawrence MA, Dickie S \& Woods JL (2018) Do nutrientbased front-of-pack labelling schemes support or undermine food-based dietary guideline recommendations? Lessons from the Australian Health Star Rating system. Nutrients 10, 32.

9. mpconsulting (2018) Reports on submissions of the Five Year Review of the Health Star Rating System. http:// healthstarrating.gov.au/internet/healthstarrating/publishing. nsf/content/formal-review-of-the-system-after-five-years (accessed November 2018).

10. Health Star Rating Advisory Committee (2017) Two year progress review report on the implementation of the Health Star Rating system. http://healthstarrating.gov.au/internet/ healthstarrating/publishing.nsf/Content/reviews (accessed March 2018).

11. Australian Government Department of Health and Ageing (2017) Campaign Materials Evaluation Research. http:// healthstarrating.gov.au/internet/healthstarrating/publishing. nsf/Content/formative-research (accessed August 2018).

12. Mortimer G \& Grimmer L (2018) Love them or loathe them, private label products are taking over supermarket shelves. https://theconversation.com/love-them-or-loathe-them-privatelabel-products-are-taking-over-supermarket-shelves-98465 (accessed November 2018).

13. Ahuja JKC, Pehrsson PR, Cogswell M et al. (2017) A comparison of concentrations of sodium and related nutrients (potassium, total dietary fiber, total and saturated fat, and total sugar) in private-label and national brands of popular, sodium-contributing, commercially packaged foods in the United States. J Acad Nutr Diet 117, 770-777.

14. Faulkner GP, Livingstone MB, McCaffrey TA et al. (2014) Supermarket own brand foods: lower in energy cost but similar in nutritional quality to their market brand alternatives. J Hum Nutr Diet 27, 617-625.

15. Khalatbari-Soltani S \& Marques-Vidal P (2016) Not as bad as you think: a comparison of the nutrient content of best price and brand name food products in Switzerland. Prev Med Rep 3, 222-228.

16. Trevena H, Neal B, Dunford E et al. (2015) A Comparison of the sodium content of supermarket private-label and branded foods in Australia. Nutrients 7, 7027-7041.

17. Dunford E, Webster J, Metzler AB et al. (2012) International collaborative project to compare and monitor the nutritional composition of processed foods. Eur J Prev Cardiol 19, $1326-1332$.

18. Food Standards Australia New Zealand (2014) AUSNUT 2011-13 food details file. http://www.foodstandards.gov. $\mathrm{au} /$ science/monitoringnutrients/ausnut/ausnutdatafiles/Pages/ fooddetails.aspx (accessed April 2018).

19. Food Standards Australia New Zealand (2015) AUSNUT 201113 food and dietary supplement classification system. http:// www.foodstandards.gov.au/science/monitoringnutrients/ ausnut/ausnutdatafiles/Pages/foodclassification.aspx (accessed April 2018).

20. Woolworths Group Limited (2018) Making healthier choices easier: The Health Star Rating System. https://www.wool worths.com.au/Shop/Discover/healthy-eating/health-star-rating (accessed August 2018).

21. Coles Supermarkets Australia Pty Ltd (2018) Healthy communities. https://www.coles.com.au/corporate-responsibility/ community/healthy-communities (accessed August 2018).

22. Ni Mhurchu C, Eyles H \& Choi YH (2017) Effects of a voluntary front-of-pack nutrition labelling system on packaged food reformulation: the Health Star Rating system in New Zealand. Nutrients 9, 918.

23. Carter OB, Mills BW, Lloyd E et al. (2013) An independent audit of the Australian food industry's voluntary front-ofpack nutrition labelling scheme for energy-dense nutritionpoor foods. Eur J Clin Nutr 67, 31-35.

24. Australian Government Department of Health (2015) Australian Dietary Guidelines 1-5. https://www.eatforhealth. gov.au/guidelines/australian-dietary-guidelines-1-5 (accessed August 2018).

25. Menday H, Neal B, Wu JHY et al. (2017) Use of added sugars instead of total sugars may improve the capacity of the Health Star Rating system to discriminate between core and discretionary foods. J Acad Nutr Diet 117, 1921-1930. 